\title{
Morphology of Piriformis- its clinical implications in Piriformis syndrome
}

\section{Harsimarjit Kaur ${ }^{1}$, Rimple Bansal *2, Gurdeep S Kalyan ${ }^{3}$, Ruchi Goyal 4.}

${ }^{1}$ Associate professor, Department of Anatomy, GMC Patiala, Punjab, India.

${ }^{* 2}$ Assistant professor, Department of Anatomy, GMC Patiala, Punjab, India.

${ }^{3}$ Professor \& Head, Department of Anatomy, GMC Patiala, Punjab, India.

${ }^{4}$ Assistant professor, Department of Anatomy, GMC Patiala, Punjab, India.

\section{ABSTRACT}

Background and Aim: Anatomical variations of neuromuscular structures of gluteal region are common. Each and every anatomical variation reflects a different and case specific clinical presentation. Piriformis is the key muscle to this region. This work was done to re-investigate the morphology of this muscle and structures related to it, in sufficient number of specimens to correlate with clinical syndrome.

Materials and Methods: 60-lower extremities with gluteal region belonging to 30 embalmed adult human cadavers named as specimens comprised the material for this study. Gluteal region was dissected to see the variations in the origin, insertion and accessory slips of piriformis muscle.

Results and Conclusion: Out of 60 specimens, piriformis consisted of one belly in 55 specimens (91.67\%) and two bellies were observed in 5 specimens (8.33\%). In two specimens belonging to one male cadaver, the piriformis was found being pierced by common trunk for inferior gluteal and common peroneal nerves whereas in three specimens piriformis was also being pierced by one root of posterior cutaneous nerve of thigh An accessory muscle was observed bilaterally in one cadaver. This accessory muscle was present below the piriformis on right side\& it was related with the emergence of tibial nerve in between the piriformis and accessory muscle which is a rare pattern. On left side this accessory muscle was present above the piriformis \& was associated with presence of superficial branch of superior gluteal artery between the upper border of piriformis and this accessory muscle. All these variations should be kept in mind during physical examination or evaluating radiological images of patients with low back pain.

KEY WORDS: Anatomical variation, Piriformis, Pirifomis syndrome, extraspinal sciatic

Corresponding Author: Dr. Rimple Bansal, Assistant professor, Department of Anatomy, GMC Patiala, Punjab, India. Phone no 09417846363 E-Mail: rimpledr79@gmail.com

Access this Article online

Quick Response code

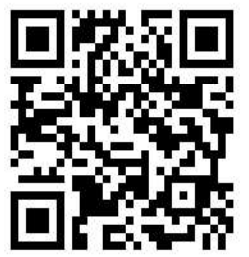

DOI: $10.16965 /$ ijar.2020.249

Journal Information

\section{International Journal of Anatomy and Research}

ISSN (E) 2321-4287 | ISSN (P) 2321-8967

https://www.ijmhr.org/ijar.htm

DOI-Prefix: https://dx.doi.org/10.16965/ijar

\section{(cc) $\mathrm{B} Y-\mathrm{NE}-\mathrm{BH}$}

\section{Article Information}

Received: 10 Dec 2020

Peer Review: 11 Dec 2020

Revised: None
Accepted: 27 Jan 2021

Published (O): 20 Feb 2021

Published (P): 05 Mar 2021

\section{INTRODUCTION}

The role of the lower limb muscles in equilibrium during locomotion and while standing has often been overlooked. Most of the muscles act mainly from their distal attachments. During both standing and walking, often the distal attachment is fixed and the proximal one is free to move, as in the case of gluteus medius which acts as a hip stabilizer rather than as an abductor [1].

The piriformis is the uppermost of the short external rotators of the hip and key to the arrangement of nerves and vessels in gluteal region. It largely fills the greater sciatic foramen, through Which the important neurovascular structures leave the pelvis thus closely 
related to this muscle. The superior gluteal nerve appears at its upper border while the pudendal nerve, the inferior gluteal nerve, the sciatic nerve and the posterior cutaneous nerve of thigh (posterior femoral cutaneous nerve) appear near its lower border [2]. This muscle takes origin from anterior surface of sacrum, gluteal surface of ilium near the posterior inferior iliac spine and capsule of adjacent sacroiliac joint, passes out of pelvis through greater sciatic foramen and gets inserted into the medial side of the upper border of greater trochanter of femurvia a rounded tendon [1].

Variations exist in various structures of the lower limb. Some are functionally insignificant but because of their clinical importance none of them should be ignored. The piriformis muscle is a short external rotator of the hip. The most frequent variation is the division of the muscle into two parts [3] and is usually associated with a high division of sciatic nerve, with emergence of peroneal portion between the two parts. Tibial division or the sciatic trunk rarely divides the muscles. The cleavage generally affects only the muscle belly, rarely it may involve the entire muscle [4]. Aberrant slips of muscle may arise in the buttock, close to the piriformis and may cause sciatica-like pain due to abnormal relation of the sciatic nerve with it [2]. Anatomical variations in human body may reflect different and a case specific clinical presentation which requires a detailed description of anatomical variations, thus it was felt worthwhile to reinvestigate the morphology of piriformis muscle and structures related to it, in sufficient number of specimens to correlate with clinical syndrome.

Aims: The present study was being conducted with the following aims:

1. To study the normal and variant morphology of piriformis muscle.

2. To compare the variations (if present) on both sides.

3. To analyse the clinical correlation related to variations so recorded and to compare the present study with the literature available.

\section{MATERIALS AND METHODS}

An observational, cross sectional study was carried out in 60-lower extremities with gluteal region belonging to 30 embalmed adult human cadavers named as specimens from the department of anatomy, Govt Medical College, Patiala, Punjab. The cadavers were labelled from 1-30 with suffix $R$ (right) or $L$ (left) and $M$ (male) or $\mathrm{F}$ (female). Consent was not required as the study done on cadavers.

Structures under cover of gluteus maximus were exposed by dissection. Conical piriformis muscle was cleaned up to its full length. Variations in origin, insertion and accessory slips of piriformis muscle were noted \& photographed.

\section{RESULTS}

The material for this study comprised of 60 gluteal regions named as specimens. Of these 60 specimens, 52 were of male and 8 were of female cadavers. The piriformis muscle and its relation with the nerves of sacral plexus emerging from greater sciatic foramen was observed in all specimens. Out of 60 gluteal regions dissected, the piriformis consisted of a single belly in 55 specimens (91.67\%) where as in rest of 5 specimens (8.33\%), the piriformis was seen being consisted of two bellies.

In two specimens $14 \mathrm{R} \& 14 \mathrm{~L}$ (Figure 1) belonging to one male cadaver, the piriformis was found being pierced by common trunk for inferior gluteal and common peroneal nerves whereas in three specimens (17R, 26L, 26R), piriformis was also being pierced by one root of posterior femoral cutaneous nerve in addition to inferior gluteal and common peroneal nerves ( Figure 2). Of these 3 specimens, 2 specimens $(26 \mathrm{R}, 26 \mathrm{~L})$ belonged to one male cadaver whereas one (17R) belonged to a female cadaver. So bilateral variations were seen in two cadavers.

Bilateral accessory muscle was seen in one cadaver ie cadaver no 19 . On the right side it was present below the piriformis muscle (Figure 3) and was running parallel to piriformis from greater sciatic notch. This accessory muscle was joining the piriformis and had a common insertion on the greater trochanter. It was further observed that common peroneal nerve, inferior gluteal nerve and one root of posterior femoral cutaneous nerve of the thigh were emerging at the upper border of 


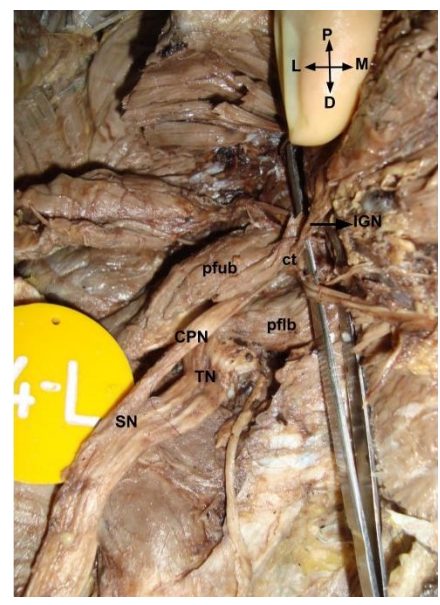

Fig. 1: showing two bellies of piriformis

CPN-common peroneal nerve, Ct-common trunk, D-distal, IGN-inferior gluteal nerve, L-lateral, M-medial, pfub-piriformis upper belly, pflb-piriformis lower belly, P-proximal, TN-tibial nerve, SN-sciatic nerve)

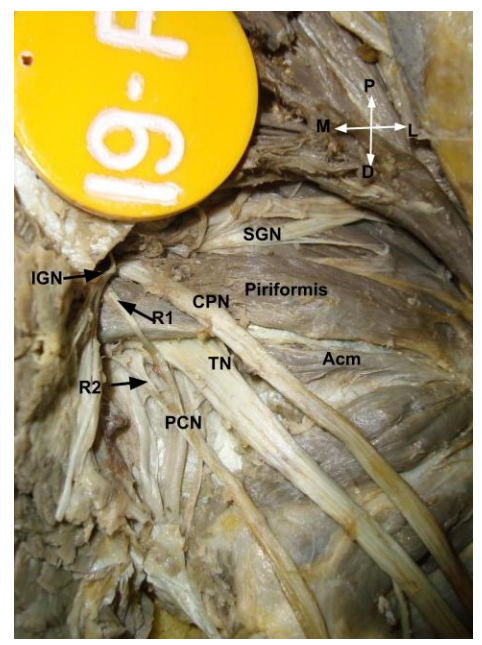

Fig. 3: showing accessory muscle below the main piriformis (Acm-Accessory muscle, CPN-common peroneal nerve, D-distal, IGN-inferior gluteal nerve, L-lateral,M-medial, P-proximal, PCN-posterior cutaneous nerve of thigh, R1 \&R2- roots of PCN, SGN-superior gluteal nerve, TN-tibial nerve)

piriformis whereas second root of posterior femoral cutaneous nerve and tibial nerve were emerging between the piriformis and accessory muscle, whereas on left side this accessory muscle was present in the gluteal region at the superior border of piriformis which was taking origin along with gluteus maximus near the greater sciatic foramen. Then accessory muscle was merging with piriformis near its insertion and had a common insertion with piriformis, two gemelli and obturator internus on the greater trochanter (Figure 4). It was further observed that superficial branch of superior gluteal artery pierced the gluteus maximus by passing between the superior margin of piriformis

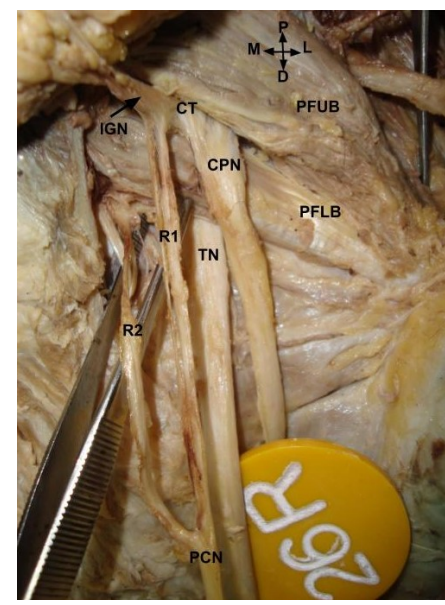

Fig. 2: showing two bellies of piriformis (CPN-common peroneal nerve, CT-common trunk D-distal, IGN-inferior gluteal nerve, L-lateral,M-medial, PFUB-piriformis upper belly, PFLB-piriformis lower belly, P-proximal, PCNposterior cutaneous nerve of thigh, R1 \&R2- roots of PCN, TN-tibial nerve)

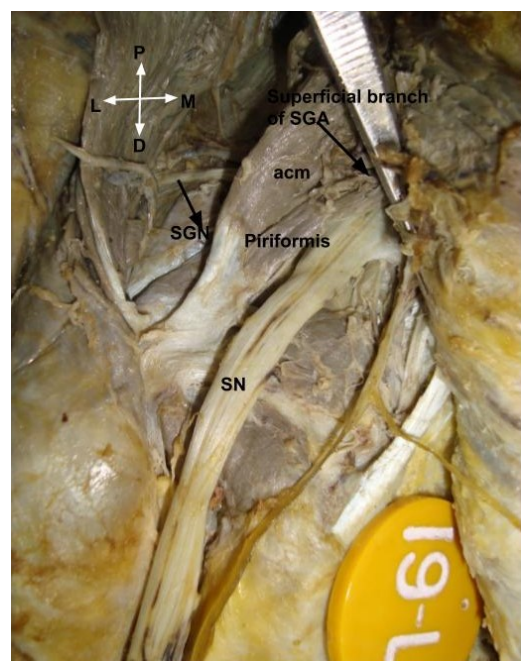

Fig. 4: showing accessory muscle above the main piriformis (Acm-Accessory muscle, D-distal, L-lateral, M-medial, P-proximal, SN-sciatic nerve, SGA-superior gluteal artery, SGN-superior gluteal nerve)

and an accessory muscle whereas the superior gluteal nerve was seen emerging above an accessory muscle before supplying the gluteus medius, minimus and tensor fascia lata. Both these accessory muscles were supplied by nerve to piriformis

\section{DISCUSSION}

It is not rare for the piriformis to be penetrated by some structures which are supposed to pass through the greater sciatic foramen in the normal anatomical position. In present study piriformis consisted of one belly in 55 specimens (91.67\%) and two bellies of piriformis were observed in 5 specimens (8.33\%). Anson and Mcvay [4] studied piriformis in 
relation to sciatic nerve in 2000 extremities. They found one belly of piriformis in $89.7 \%$ cases and two bellies of piriformis in $10.3 \%$ cases. In a study of 40 gluteal region, Vicente [5] et al found one belly of piriformis in $90 \%$ and two bellies in $10 \%$ cases. Guvencer [6] et al found two bellies in $12 \%$ cases. Eastlack [7] et al studied sciatic neuromuscular variants on MR neurography and found double bellies in $11.9 \%$ cases. (Table 1 )

Table 1: Number of bellies of piriformis: Comparison of present study with earlier published data.

\begin{tabular}{lcc}
\hline \multicolumn{1}{c}{ Author \& Year } & One belly & Two bellies \\
\hline Anson \& Mcvay (1971) [4] & $89.70 \%$ & $10.30 \%$ \\
Vicente et al (2007) [5] & $90 \%$ & $10 \%$ \\
Guvencer et al (2009) [6] & $84 \%$ & $16 \%$ \\
Eastlack et al (2017) [7] & $88.10 \%$ & $11.90 \%$ \\
\hline Present study & $91.67 \%$ & $8.33 \%$ \\
\hline
\end{tabular}

In present study an accessory muscle was observed bilaterally in one of the cadaver. This accessory muscle was present below the piriformis on right side $\&$ it was associated with the emergence of common peroneal nerve, inferior gluteal nerve and one root of posterior cutaneous nerve of the thigh above the piriformis whereas second root of posterior cutaneous nerve of thigh and tibial nerve were emerging between the piriformis and accessory muscle. This is a rare variant pattern and has not been reported in the literature so far. In a study done by Eastlack [7] et al by using MR neurography, they found a variant pattern in which common peroneal nerve and tibial nerve exited below the piriformis but were divided by a thin fibrous strip in 9 out of 268 extremities. So the variant pattern seen in present study remains unclassified according to Beaton \& Anson [8] classification as well as simplified classification system given by Eastlack [7] et al. On left side this accessory muscle was present above the piriformis. This was associated with emergence of superficial branch of superior gluteal artery between the superior margin of piriformis and an accessory muscle. Prasad [9] et al found double piriformis with separate origins and insertions. The superior gluteal nerve and vessels passed between the two heads which may get compressed if the muscle hypertrophies. However in present study, the superficial branch of superior gluteal artery not the superior gluteal nerve was emerging between the superior margin of piriformis and an accessory muscle as seen in left side of same cadaver.

Ravindranath [10] et al found an accessory slip of the piriformis in three male cadavers. The main trunk of the sciatic nerve was found deep to the accessory slip. But in present study no such relation of sciatic nerve with accessory muscle was observed.

The two bellies of piriformis can be related to embryonic development of the sciatic nerve by joining of tibial and common peroneal nerves which are connected together by connective tissue sheath. These two nerves may separate and may have a separate exit that seems to be dividing the piriformis into bellies. Therefore it can be explained that the division of piriformis into two bellies is related to development of sciatic nerve.

The piriformis may compress the sciatic nerve and cause the Piriformis Syndrome also known as pseudo sciatica, nondiscogenic sciatica or wallet sciatica [11]. Piriformis syndrome (PS) not only occurs due to hypertrophy, inflammation or irritation of normal muscle, but also may be caused by congenital variations of the piriformis and sciatic nerve [6].

Piriformis syndrome may occur as blunt trauma to buttock. Intraoperative findings revealed adhesions between piriformis, the sciatic nerve and the roof of the greater sciatic notch. Release of piriformis tendon and sciatic neurolysis led to encourage with few complications [12].

Hollinshead [2] stated that aberrant slips of muscle may arise in the buttock, commonly close to or with the piriformis muscle as seen in two specimens of present study. Embryologically these variations are considered to be due to the persistence of an undifferentiated group of mesenchymal cells. There was no limitations in procurement of number of cadavers for the study, however if the sample size could have been more the accuracy of the result could have been better.

\section{CONCLUSION}

Piriformis muscle anatomy is variable and has 
important clinical implications. It is very important to consider these variations in practice, as such variations may go undiagnosed. It is further commented that these variations are not a rare phenomenon but are quite common. If rare variant pattern as seen in our study along with other variations are kept in mind, advanced imaging techniques are able to diagnose such cases in life and can be treated accordingly.

\section{ACKNOWLEDGEMENTS}

We are thankful to those noble souls without whom this study could not have accomplished.

\section{Conflicts of Interests: None}

\section{REFERENCES}

[1]. Williams A \& Newell RLM. General organization and surface anatomy of lower limb. In: Standring S. Gray's Anatomy. The anatomical basis of clinical practice, Elsevier Churchill Livingstone, $39^{\text {th }}$ Edition; 2004: 1399-400.

[2]. Hollinshead WH. Buttock, hip joint, and thigh. In Anatomy for Surgeons. The back and limbs, Vol 3. Hoeber \& Harper, New York, $1^{\text {st }}$ Edition; 1958: 6908.

[3]. Arifoglu Y, Surucu HS, Sargon MF, Tanyeli E, Yagar F. Double superior gemellus together with double piriformis and high division of sciatic nerve. Surg Radiol Anat 1997; 19: 407-8.

[4]. Anson BJ and Mcvay CB. Surgical Anatomy, WB Saunders Company/ Philadelphia London Toronto, $5^{\text {th }}$ Edition; 1971: 1087-8.

[5]. Vicente EJD, Viotto MJS, Barbosa CAA, Vicente PC. Study on anatomical relationships and variations between the sciatic nerve and piriformis muscle. Rev. bras. Fisioter. 2007; 11(3) Sao Carlos: 1-8.
[6]. Guvencer M, Akyer P, Ýyem C, Tetik S, Naderi S. Variations in the high division of the sciatic nerve and relationship between the sciatic nerve and the piriformis. Turk Neurosurg 2009; 19(2): 139-44.

[7]. Eastlack J,Tenorio L,Wadhwa V,Scott K,Starr A,Chhabra A.Sciatic neuromuscular variants on MR neurography:frequency study and interobserver performance. Br J Radiol 2017; 90:20170116.

[8]. Beaton LE, Anson BJ. The relation of sciatic nerve and of its subdivisions to the piriformis muscle.Anat Rec 1937; 70: 1-5

[9]. Prasad AM, Nayak SB, Deepthinath R, Vollala VR, Bhat $S$. Clinically important variations in the lower limb - A case report. Eur J Anat 2005; 9(3): 167-9.

[10]. Ravindranath Y, Manjunath KY, Ravindranath R. Accessory origin of the piriformis muscle. Singapore Med J 2008; 49: 217-8.

[11]. Natsis K, Totlis T, Konstantinidis GA, Paraskevas G, Piagkou M, Koebke J. Anatomical variations between the sciatic nerve and the piriformis muscle: a contribution to surgical anatomy in piriformis syndrome. Surg Radiol Anat. 2014; 36: 273-80.

[12]. Benson ER \& Schutzer SF. Posttraumatic Piriformis syndrome: Diagnosis and Results of Operative Treatment. The J of Bone and Joint Surgery 1999; 81: 941-9.

How to cite this article:

Harsimarjit Kaur, Rimple Bansal, Gurdeep S Kalyan, Ruchi Goyal. Morphology of Piriformis- its clinical implications in Piriformis syndrome. Int J Anat Res 2021;9(1.2):7869-7873. DOI: 10.16965/ ijar.2020.249 